\title{
1 Insights into the evolution of mesophily from the bacterial phylum Thermotogae
}

3 Stephen M. J. Pollo, Olga Zhaxybayeva, Camilla L. Nesbø

4

5 Stephen M. J. Pollo

6 Department of Biological Sciences, 11455 Saskatchewan Drive, University of Alberta, Edmonton,

$7 \quad$ Alberta, Canada, T6G 2E9. pollo@ualberta.ca

8 Olga Zhaxybayeva

9 Department of Biological Sciences and Department of Computer Science, Dartmouth College, 78

10 College Street, Hanover, NH, 03755, U.S.A. olga.zhaxybayeva@dartmouth.edu

11 Camilla L. Nesbø

12 Department of Biological Sciences, 11455 Saskatchewan Drive, University of Alberta, Edmonton,

13 Alberta, Canada, T6G 2E9 and Centre for Ecological and Evolutionary Synthesis (CEES),

14 Department of Biology, University of Oslo, P.O. Box 1066 Blindern, N-0316 Oslo,

15 Norway. nesbo@ualberta.ca and c.l.nesbo@bio.uio.no

16

17 Corresponding Author:

18 Camilla L. Nesbø

19 Department of Biological Sciences, CW 405 Biological Sciences Bldg., 11455 Saskatchewan

20 Drive, University of Alberta, Edmonton, Alberta, Canada, T6G 2E9. Telephone: (01) 780-492-

218956 nesbo@ualberta.ca and c.l.nesbo@bio.uio.no

22 Running Title: Temperature adaptation in Thermotogae 
23 Abstract: Thermophiles are extremophiles that grow optimally at temperatures $>45^{\circ} \mathrm{C}$. In order

24 to survive and maintain function of their biological molecules, they have a suite of characteristics

25 not found in organisms that grow at moderate temperature (mesophiles). At the cellular level,

26 thermophiles have mechanisms for maintaining their membranes, nucleic acids and other cellular

27 structures. At the protein level, each of their proteins remains stable and retains activity at

28 temperatures that would denature their mesophilic homologs. Conversely, cellular structures and

29 proteins from thermophiles may not function optimally at moderate temperatures. These

30 differences between thermophiles and mesophiles presumably present a barrier to evolutionary

31 transitioning between the two lifestyles. Therefore, studying closely related thermophiles and

32 mesophiles can help us determine how such lifestyle transitions may happen. The bacterial

33 phylum Thermotogae contains hyperthermophiles, thermophiles, mesophiles and organisms with

34 temperature ranges wide enough to span both thermophilic and mesophilic temperatures.

35 Genomic, proteomic and physiological differences noted between other bacterial thermophiles

36 and mesophiles are evident within the Thermotogae. We argue that the Thermotogae is an ideal

37 group of organisms for understanding both the response to fluctuating temperature as well as

38 long-term evolutionary adaptation to a different growth temperature range.

40 Key Words: lateral gene transfer, Kosmotoga, Mesotoga, thermostability, stress response 


\section{Introduction}

43 Extremophiles are organisms that thrive under extreme environmental conditions unsuitable for

44 survival of most other organisms. As such, they are of great interest for delineating the limits of

45 conditions that permit life's existence, a key insight needed to advance efforts in the search for

46 life on Earth and other planets (Pikuta et al. 2007; Rothschild and Mancinelli 2001). Additionally,

47 due to their intrinsically "extreme” nature, these organisms are also desirable sources of enzymes

48 and other biomolecules that function under conditions that render other organisms and their

49 enzymes inactive. Such biomolecules may have a wide range of biotechnological and industrial

50 applications from clean energy to bioremediation and carbon sequestration.

51 When examining temperature as a parameter that can either permit or exclude life, there

52 are mesophiles, the organisms that grow optimally at moderate temperatures, and two types of

53 extremophiles: psychrophiles, which grow optimally at temperatures below $15^{\circ} \mathrm{C}$, and

54 thermophiles, which grow optimally at temperatures above $45^{\circ} \mathrm{C}$ (Kimura et al. 2013). Within

55 thermophiles, organisms growing optimally at $>80^{\circ} \mathrm{C}$ are commonly referred to as

56 hyperthermophiles. Thermophiles are of particular interest due to their ability to withstand the

57 denaturing effect of higher temperatures on biological molecules such as proteins and DNA (Li et

58 al. 2005).

59 The phylogenetic position of the hyperthermophile-containing bacterial lineages

60 Thermotogae, Thermodesulfobacteria and Aquificae at, or close to, the base of the 16S rRNA tree

61 of life (Fig. 1), has been used as support for the hypothesis that the ancestor of the bacterial

62 domain was a hyperthermophile (Achenbach-Richter et al. 1987). Similarly, thermophilic

63 Archaea are also found at the base of the Archaeal domain (Fig. 1). Together with the proposed

64 high temperature conditions of early Earth this led to the hypothesis that the last universal 
65 common ancestor (LUCA) was a hyperthermophile (Pace 1991). A (hyper)thermophilic LUCA is

66 also supported by experimental evidence from resurrection of ancestral nucleoside diphosphate

67 kinases and characterizing their properties (Akanuma et al. 2013). Other lines of evidence,

68 however, suggest that the LUCA may have been either a mesophile or a thermophile growing

69 optimally below $80^{\circ} \mathrm{C}$ (Boussau et al. 2008; Brochier-Armanet and Forterre 2006). Whether the

70 LUCA lived at the time of life's origin or much later remains debatable as well (Zhaxybayeva and

71 Gogarten 2004).

72 Regardless of the optimal growth temperature of the LUCA, the ancestors of present day

73 bacterial and archaeal lineages have had to modify their cellular structures and protein

74 compositions to transition between mesophilic and thermophilic lifestyles (Boussau et al. 2008).

75 Given the distribution of mesophiles and thermophiles on the Tree of Life (Fig. 1), we infer that

76 such transitions likely happened independently multiple times. This same inference has been

77 made based on multivariate analyses of the amino acid compositions of 279 prokaryotes (Puigbò

78 et al. 2008) and from the different mechanisms of DNA supercoiling and the phylogeny of the

79 involved genes (López-García 1999). This conjecture is also supported by reconstruction and

80 synthesis of ancestral versions of enzymes and examining the optimal temperature at which they

81 function. For example, examination of LeuB enzymes (3-isopropylmalate dehydrogenase) in the

82 Bacillus genus suggests multiple transitions between thermophilic and mesophilic temperature

83 optima when going forward in evolutionary time from the Bacillus ancestor (Hobbs et al. 2012).

84 Therefore, thermophily has been lost and gained throughout the evolutionary history of the genus

85 Bacillus. Similarly, analysis of extant and reconstructed ancestral myo-inositol-3-phosphate

86 synthase enzymes from Thermotoga and Thermococcales suggests higher optimal growth

87 temperatures of the ancestors (Butzin et al. 2013), indicating fluctuations of the tolerated 
88 temperature ranges of these organisms throughout their evolutionary history. Together these

89 studies imply that temperature adaptations may not be too difficult, and the growth temperature

90 range may change rapidly and frequently in many lineages.

91 Temperature adaptation can be defined either as a response of an individual cell to

92 changes in temperature, or as an evolutionary adaptation of an organismal lineage (such as

93 'species') to growth within a certain temperature range. To distinguish between the two, we will

94 refer to temperature response for the former and temperature adaptation for the latter. These two

95 phenomena are related, as selection acting on temperature responses may eventually lead to

96 temperature adaptations. In this review we focus on organismal responses and lineage adaptations

97 to moderate and high temperatures. For a review of adaptation to very low growth temperatures

98 see Siddiqui et al. (2013). Specifically, we will discuss properties of thermophiles, and how these

99 properties may relate to a transition between thermophily and mesophily, with a particular

100 emphasis on the bacterial phylum Thermotogae.

101

102 The Thermotogae

103 Bacteria belonging to the Thermotogae phylum were first isolated by Karl Stetter and colleagues

104 in 1986 from geothermally heated sea floors (Huber et al. 1986). Their name derives from the

105 unique outer sheath-like structure that balloons over each end of the cell, known as the "toga"

106 (Fig. 2) (Huber et al. 1986). There are 12 described genera in this phylum, most of which are

107 thermophiles (Fig. 3). In the accepted taxonomy, these genera are all grouped in a single order,

108 Thermotogales, and one family, Thermotogaceae. However, a reclassification of these bacteria

109 into separate orders is overdue, and a division into three orders and four families has been 
110 recently proposed (Bhandari and Gupta (2014); Fig. 3). While the new classification is based on

111 conserved indels, it is consistent with the 16S rRNA phylogeny (Fig. 3).

112 Thermotogae are anaerobes and organotrophs, capable of growing on a wide range of

113 complex substrates (Conners et al. 2006). They are found in hot ecosystems all over the world

114 including thermal springs, hydrothermal vents, and petroleum reservoirs (Huber and Hannig

115 2006; Ollivier and Cayol 2005), with some members growing at temperatures up to $90^{\circ} \mathrm{C}$.

116 Although it was long thought that the Thermotogae only harbored thermophiles and

117 hyperthermophiles (11 of 12 genera are entirely composed of thermophiles or

118 hyperthermophiles) (Fig. 3), mesophilic Thermotogae from the genus Mesotoga have recently

119 been detected and isolated from cool hydrocarbon-impacted sites such as oil reservoirs and

120 polluted sediments (Ben Hania et al. 2011; Ben Hania et al. 2013; Nesbø et al. 2006b; Nesbø et

121 al. 2010; Nesbø et al. 2012). Interestingly, the closest relative of Mesotoga, Kosmotoga olearia,

122 has an unusually wide growth temperature range, which may have been important in Mesotoga's

123 adaptation to low temperature (DiPippo et al. 2009; Nesbø et al. 2012).

124 As of May 2015, over 80 completed and ongoing Thermotogae genome projects

125 comprise 10 of the 12 described Thermotogae genera, with no genome projects for Geotoga nor

126 Oceanotoga (Benson et al. 2014; Reddy et al. 2014). The maximum divergence in the $16 \mathrm{~S}$ rRNA

127 genes of these cultivated Thermotogae is $25 \%$, similar to what is observed for other bacterial

128 phyla (Konstantinidis and Tiedje 2005). For protein coding genes pairwise average amino acid

129 identity (AAI; Konstantinidis and Tiedje 2005) between genera ranges from 45 to 69\% (average

130 49\%). Phylogenetic analysis of environmental 16S rRNA gene sequences shows several novel

131 Thermotogae lineages without any cultivated members, and based on the nucleotide identity they

132 would be classified as new genera (Nesbø et al. 2010). Thus, as with most microbial lineages, 
133 there is a large unknown diversity of Thermotogae. At least four of these new lineages have only

134 been detected in low temperature environments (as low as $9.5^{\circ} \mathrm{C}$ ), suggesting that Thermotogae

135 might be common in mesothermic environments. Interestingly, on the phylogenetic tree these

136 likely mesophilic lineages fall within multiple thermophilic clades (Nesbø et al. 2010),

137 suggesting several independent adaptations to lower temperatures.

138 With mesophilic Thermotogae only recently discovered, the functional characterization of

139 this phylum has focused on thermophiles, mainly the hyperthermophilic organisms Thermotoga

140 maritima and Thermotoga neapolitana. Protein crystal structures have also been experimentally

141 determined for a large portion of the T. maritima proteome (DiDonato et al. 2004; Lesley et al.

142 2002), and the protein structures of its central metabolic networks were modeled by Zhang et al.

143 (2009). Complimented with models of high temperature hydrogen and sulfur metabolism

144 (Cappelletti et al. 2014; Schut et al. 2012), this wealth of functional information makes the

145 Thermotogae a promising microbial lineage for industrial and biotechnological applications. For

146 example, most Thermotogae produce hydrogen that may be harvested (e.g., Nguyen et al. (2008)

147 and Maru et al. (2012)). The hydrogen production of T. maritima can be boosted via metabolic

148 engineering, as was demonstrated by an in silico re-design of its metabolism (Nogales et al. 2012).

149 Additionally, while the degradation of sugars by many Thermotogae results in the production of

$150 \mathrm{CO}_{2}$ and acetate, $T$. neapolitana has been shown to convert these by-products to lactic acid when

151 grown in a $\mathrm{CO}_{2}$ atmosphere, a process suggested to have potential in carbon capture (D'Ippolito et

152 al. 2014).

153 Carbohydrate utilization by T. maritima has been examined by studying the substrate

154 specificities and affinities of its carbohydrate transporters (Boucher and Noll 2011; Cuneo et al.

155 2009; Ghimire-Rijal et al. 2014; Nanavati et al. 2005; Nanavati et al. 2006) and their 
156 transcriptional regulation in response to growth on different saccharides (Frock et al. 2012).

157 Information about substrate specificities, enzymatic activities and catalytic mechanisms of many

158 of T. maritima's glycoside hydrolases are also available (Arti et al. 2012; Comfort et al. 2007;

159 Kleine and Liebl 2006), which has been used, for instance, to engineer an alpha-galactosidase

160 from T. maritima into an efficient alpha-galactosynthase (Cobucci-Ponzano et al. 2011). The

161 transcriptional regulation of glycoside hydrolases and other carbohydrate metabolism-related

162 genes in response to growth on various carbohydrates highlights the differences in carbohydrate

163 utilization, even between closely related Thermotogae lineages (Chhabra et al. 2002; Chhabra et

164 al. 2003; Frock et al. 2012). Moreover, interconnections exist between sugar regulons in $T$.

165 maritima's carbohydrate utilization network, suggesting coordinated regulatory responses to

166 particular types of complex carbohydrates (Rodionov et al. 2013). This rich knowledge base will

167 be very useful in comparative studies of thermophilic and mesophilic Thermotogae lineages and,

168 ultimately, will lead to understanding processes leading to shifts in an organism's growth

169 temperature range.

171 General cellular adaptations to thermophily

172 Regardless of whether cells are responding to transient temperature increases within their growth

173 range or evolving to an alternate growth range, changes in temperature require major

174 modifications across the cell to optimize cell function and growth. The following sections discuss

175 some of these temperature responses and adaptations in microbial cells.

177 The effect of temperature on cellular membranes: maintaining a fluid envelope 
178 The cell membrane is critical to cell function since it maintains and separates the interior cell

179 environment from the exterior environment. In order to serve its function, a lipid membrane must

180 be impermeable to most solutes and maintain a liquid crystalline phase, even under stress (de

181 Mendoza 2014). As the temperature increases, membrane integrity and impermeability become

182 compromised, which eventually results in cell death (Chang 1994). Therefore, thermophiles must

183 maintain their membranes under conditions that could inactivate those of mesophiles. Bacteria

184 and Archaea handle this challenge differently due to the dissimilar structures of their membrane

185 lipids (reviewed in detail by Oger and Cario (2013), Koga and Morii (2005), Koga (2012), and

186 Mansilla et al. (2004)). We will only focus on bacterial lipids here. For a review on archaeal lipids

187 see Oger and Cario (2013).

188 Bacterial polar membrane lipids consist mainly of straight-chain fatty acids that are bound

189 to the polar head group predominantly by ester linkages (Koga and Morii 2005). Bacteria respond

190 to various temperatures by altering the composition (length, degree of branching and degree of

191 unsaturation) of their fatty acid chains to maintain membrane fluidity (Mansilla et al. 2004; Zhang

192 and Rock 2008). The types of fatty acids bacteria are able to produce will therefore influence the

193 temperature range within which they can grow. For example, hyperthermophilic Thermotogae

194 have unusual membrane-spanning diabolic fatty acids in their membrane, which are thought to be

195 an adaptation to high temperature growth (Carballeira et al. 1997; Damsté et al. 2007). In

196 agreement with this hypothesis, these diabolic fatty acids are not found in the membranes of the

197 mesophilic Mesotoga prima (Nesbø et al. 2012). Moreover, M. prima (grown at $35^{\circ} \mathrm{C}$ ) contained

198 branched, mono-unsaturated and saturated fatty acids, while K. olearia (grown at $55^{\circ} \mathrm{C}$ ) contained

199 only saturated fatty acids (Nesbø et al. 2012). Fatty acid composition is also part of the immediate

200 cold-shock response with genes involved in production of, for instance, branched fatty-acids 
201 being up-regulated in the thermophile Thermoanaerobacter tengcongensis when grown at sub-

202 optimal temperatures (Liu et al. 2014). Increase of branched fatty acids is a common response to

203 lower temperatures (Suutari and Laakso 1994), and in Listeria monocytogenes this is due to

204 temperature-dependent substrate selectivity of FabH, the enzyme responsible for the first

205 condensation reaction in fatty acid biosynthesis (Singh et al. 2009). Interestingly, in Bacillus a

206 transmembrane two-component response regulator, which controls the desaturase that introduces

207 double bonds in preexisting fatty acids, senses changes in membrane fluidity and not the actual

208 temperature changes (de Mendoza 2014).

209 In addition to the lipid structure of cell membranes, integral membrane proteins affect the

210 temperature tolerance of an organism (Thompkins et al. 2008). Therefore, while the lipid

211 composition of the membrane is crucial for its function, integral membrane proteins may also

212 play a significant role, particularly with respect to the temperature limit of an organism's growth

213 range. For example, mutations of integral membrane proteins of the DedA family cause

214 temperature sensitivity and cell division defects in Escherichia coli (Thompkins et al. 2008).

215 Interestingly, proteins from the DedA family have been shown to be essential in at least two

216 bacterial species (E. coli and Borrelia burgdorferi), but their homologs are not detected in

217 several thermophilic and hyperthermophilic Thermotogae genomes (Doerrler et al. 2013). This

218 suggests that the function provided by DedA is either not needed by these organisms, or is being

219 provided by analogous integral membrane proteins, or that their DedA homologs are too

220 divergent to be detected by sequence similarity searches.

221

222 Nucleic acids: a challenge to keep the strands together 
223 High temperatures denature double stranded DNA and secondary structures of RNA. This

224 presents a problem for thermophiles, and for hyperthermophiles in particular. These organisms

225 must maintain their chromosomes in an orderly state for both efficient packaging as well as

226 coordinated gene expression. Therefore, to survive the damaging effects of high temperature

227 thermophiles need to either continuously repair their damaged DNA or protect it from damage in

228 the first place. For example, the archaeon Pyrococcus abyssi has a highly efficient DNA repair

229 system that continuously repairs temperature-induced DNA damage (Jolivet et al. 2003). Very

230 high levels of homologous recombination are observed in hyperthermophilic Thermotoga spp.

231 where the ratio of nucleotide changes introduced by recombination relative to point mutation

$232(r / m)$ is in the range 24-100 for genomes originating from geographically distant sites (Nesbø et

233 al. 2006a; Nesbø et al. 2014). This in the upper range of values reported in a comparison of $r / m$

234 across a large sample of mostly mesophilic Bacteria and Archaea $(0.02-64)$, where values

235 above 10 were interpreted as very high (Vos and Didelot 2009). The high level of recombination

236 may be explained by the need for DNA repair in thermophiles (Johnston et al. 2014). This

237 hypothesis is supported by observations of high levels of recombination and repair in other

238 hyperthermophilic microorganisms, such as Pyrococcus furiosus (DiRuggiero et al. 1997),

239 Sulfolobus islandicus (Whitaker et al. 2005), and Persephonella (Mino et al. 2013).

240 Protection of DNA is known to occur via multiple unrelated mechanisms. Primarily,

241 thermophiles safeguard their DNA with thermostable proteins analogous to eukaryotic histones.

242 For example, in the archaeon Thermococcus kodakaraensis HpkA and HpkB dramatically

243 increase the melting temperature of a given DNA sequence upon binding, with HpkB being able

244 to raise the melting temperature of poly(dA-dT) DNA by $>20^{\circ} \mathrm{C}$ (Higashibata et al. 1999),

245 suggesting that these proteins play a major role in the stabilization of Thermococcus 
246 kodakaraensis chromosomes. In the bacterium T. maritima the histone-like protein HU stabilizes

247 and protects the DNA (Mukherjee et al. 2008).

248 Thermophiles can also use polyamine compounds to stabilize their DNA and RNA, as

249 well as many other cellular components. Multivalent polyamine compounds such as putrescine,

250 spermidine, and spermine, or their acetylated forms, compact histone-bound DNA in

251 Thermococcus kodakaraensis, stabilizing it at temperatures as high as $90^{\circ} \mathrm{C}$ (Higashibata et al.

252 2000). In Thermotoga species the polyamines caldopentamine and caldohexamine increase in

253 concentration with increased temperature, suggesting a role in thermal response and thermal

254 adaptation (Zellner and Kneifel 1993). Indeed caldopentamine and caldohexamine, as well as five

255 other long linear polyamines found in Thermus thermophilus, have been shown to stabilize

256 double-stranded DNA at high temperature, with a greater stabilizing effect by polyamines with a

257 larger number of amino nitrogen atoms (Terui et al. 2005).

258 Thirdly, unique RNA modifications can confer thermostability in thermophiles

259 (McCloskey et al. 2001). For example, modifications from adenosine to 2'-O-methyladenosine or

260 from guanosine to $\mathrm{N}^{2}, 2^{\prime}$-O-dimethylguanosine in the tRNAs are often growth temperature-

261 specific, even among closely related lineages (McCloskey et al. 2001).

262 Lastly, thermal adaptation may be achieved via reverse gyrase-mediated DNA

263 supercoiling. Reverse gyrase is a protein found almost exclusively in hyperthermophiles and,

264 importantly, it is a gene carried by all known hyperthermophiles (Brochier-Armanet and Forterre

265 2006; Forterre 2002; Lulchev and Klostermeier 2014). While deletion of the reverse gyrase gene

266 from Thermococcus kodakaraensis results in slower growth at high temperatures $\left(90^{\circ} \mathrm{C}\right)$, it does

267 not abolish its growth, suggesting that this enzyme is not essential for hyperthermophilic growth

268 as was once thought (Atomi et al. 2004). However, since the T. kodakaraensis mutant lacking 
269 reverse gyrase grew poorly at $90^{\circ} \mathrm{C}$, and unlike the wild-type strain, could not grow above $90^{\circ} \mathrm{C}$

270 (Atomi et al. 2004), this enzyme is still considered to be a critical adaptation for optimal growth

271 at high temperatures (Brochier-Armanet and Forterre 2006). Although reverse gyrase catalyzes

272 ATP-dependent positive supercoiling of DNA in vitro, its function in vivo remains unknown. The

273 increased heat protection provided by this enzyme may be linked to a role in the DNA damage

274 response, possibly through recruitment to lesions (Lulchev and Klostermeier 2014; Perugino et al.

275 2009). Interestingly, cultivated hyperthermophilic species from both the Thermotogae and the

276 Aquificae have acquired their reverse gyrase genes from Archaea by lateral gene transfer (LGT),

277 suggesting that hyperthermophily may have been acquired by Bacteria from Archaea (Brochier-

278 Armanet and Forterre 2006; Forterre et al. 2000).

279 While some of these adaptations for nucleic acid stabilization have only been found in

280 thermophiles (e.g., reverse gyrase (Forterre 2002), certain RNA modifications (McCloskey et al.

281 2001) and thermostable histones (Higashibata et al. 1999)), others are found in mesophiles as well.

282 For instance, the same polyamines found in Thermotoga are also found in mesophilic microalgae

283 (Nishibori et al. 2009). Hence, transition between thermophily and mesophily may only require a

284 re-purposing of certain cellular constituents, rather than removing or acquiring them.

285 In addition to cellular components interacting with nucleic acids for stabilization, the

286 composition of some nucleic acids appears adapted to the thermophilic lifestyle of the host

287 organism. The extra hydrogen bond in G:C nucleotide pairs was long thought to play a part in

288 optimal growth temperature. While genome-wide $\mathrm{G}+\mathrm{C}$ content does not correlate with optimal

289 growth temperature (Galtier and Lobry 1997; Hurst and Merchant 2001; Zeldovich et al. 2007),

290 the $\mathrm{G}+\mathrm{C}$ content of some structural RNA encoding genes does. For example, the $\mathrm{G}+\mathrm{C}$ content of

291 secondary structures of rRNA and tRNA molecules, specifically in the stem structures, increases 
292 with optimal growth temperature (Galtier and Lobry 1997; Kimura et al. 2013; Zhaxybayeva et al.

293 2009). As a result, the GC content variation of the 16S rRNA gene can be used as a proxy for

294 studying temperature adaptation within the Thermotogae. For example, the temperature optimum

295 for uncultured members of the phylum was predicted by establishing a correlation between the

296 16S rRNA gene distances and optimal growth temperature of 33 Thermotogae isolates (Dahle et

297 al. 2011). Additionally, inference of the ancestral states of the 16S rRNA gene that gave rise to 30

298 Thermotogae isolates allowed Green et al. (2013) to hypothesize that the thermotolerant

299 Thermotogae lineages are under directional selection and that transition from high to low optimal

300 growth temperature is easier to achieve.

301

\section{Compatible solutes: the power of redundancy}

303 Compatible solutes are organic compounds that are accumulated by cells under stressful

304 conditions such as osmotic stress and heat stress (Santos et al. 2011). These compounds,

305 particularly polyamines, are known to stabilize nucleic acids in thermophilic cells (see above).

306 Moreover, in the bacterium Calderobacterium hydrogenophilum polyamine compounds stabilize

307 the 70S initiation complex of ribosomes (Mikulik and Anderova 1994). Many temperature studies

308 in the Thermotogae have focused on the accumulation of these organic compounds and

309 polyamines and the elucidation of their biosynthetic pathways in T. maritima and the more

310 moderate thermophile Petrotoga miotherma (Jorge et al. 2007; Oshima et al. 2011; Rodionova et

311 al. 2013; Rodrigues et al. 2009; Zellner and Kneifel 1993). Several compatible solutes have so far

312 only been found in thermophiles including di-myo-inositol phosphate, mannosyl-di-myo-inositol

313 phosphate, mannosylglyceramide, and diglycerol phosphate (Borges et al. 2010; Gonçalves et al.

314 2012) and novel thermophilic solutes continue to be identified (Jorge et al. 2007; Rodrigues et al. 
315 2009). However, while these compounds are thermophile-specific and may represent thermophile-

316 specific adaptations, they are not the only compatible solutes used to deal with heat stress. When

317 the ability to synthesize di-myo-inositol phosphate was removed from Thermococcus

318 kodakarensis by deleting a key synthesis gene, the growth of this archaeon was unaffected, and

319 aspartate accumulated as an alternative compatible solute (Borges et al. 2010). In the

320 Thermotogae multiple solutes accumulate under stress conditions (Jorge et al. 2007; Rodrigues et

321 al. 2009). This suggests that although the role compatible solutes play in thermal protection is not

322 fully understood, there is functional redundancy among the solutes.

323

324 Protein dynamics and turnover; assistance from chaperones and proteases

325 Chaperones are large protein complexes that assist the proper folding and re-folding of proteins.

326 The chaperonins represent an extensively studied subclass of chaperones with a stacked double-ring

327 structure (Large et al. 2009). Distribution of the chaperone families varies across Bacteria and

328 Archaea, and some chaperones are considered indispensable (Large et al. 2009). For example, some

329 chaperonins help fold new polypeptides, as well as re-fold and rescue proteins that have been

330 inactivated due to stress (Techtmann and Robb 2010). A major stressor that triggers chaperone-

331 mediated protein repair is heat shock, which has resulted in many chaperones being named heat

332 shock proteins (HSP) (Large et al. 2009). By preventing inactivation and aggregation of proteins at

333 high temperatures, this ubiquitous system is thought to be especially important in thermophiles,

334 which employ chaperones in both unstressed and heat-stressed states (Pysz et al. 2004). Thus, while

335 these proteins are part of high temperature response in mesophiles, their constitutive expression in

336 thermophiles may be part of their temperature adaptation. For example, the predicted chaperone

337 TM1083 in T. maritima is thought to stabilize the DNA gyrase enzyme at temperatures near optimal 
growth (Canaves 2004). Moreover, the molecular chaperone trigger factor (TM0694) from $T$.

339 maritima strongly binds model proteins and decreases their folding rate, while these activities are

340 much weaker in the homologous trigger factor from the psychrophile Pseudoalteromonas

341 haloplanktis, which instead shows increased prolyl isomerization (Godin-Roulling et al. 2014).

342 However, it should be noted that chaperones, although always highly expressed in thermophiles, are

343 part of their high temperature response as well. For instance, examination of the T. maritima

344 proteome at four temperatures spanning its growth range revealed higher relative abundance of

345 chaperones at supra-optimal temperatures (Wang et al. 2012).

346 Proteases are also part of the heat shock response in mesophilic organisms (Richter et al.

347 2010). A key distinction between well-studied bacterial mesophiles and the hyperthermophile $T$.

348 maritima is the lack of regulation in T. maritima of most of its proteases in response to

349 temperature stress (Conners et al. 2006). This may be explained by an absence of major

350 regulators of the mesophilic proteolytic response (i.e., rpoH or ctsR homologs) in the T. maritima

351 genome (Conners et al. 2006; Pysz et al. 2004). Perhaps this bacterium gains a survival

352 advantage from constitutive expression of most proteases. A similarity search revealed an

353 absence of detectable rpoH and ctsR homologs in 38 Thermotogae, including the thermophilic $K$.

354 olearia and the mesophilic M. prima, suggesting that any regulation of protease expression in the

355 Thermotogae involves different genes than those used by other Bacteria and Archaea.

\section{Thermal adaptation at the protein level}

358 Although chaperones aid in proper folding and maintenance of proteins under high temperature

359 conditions, proteins from thermophilic organisms are themselves adapted to high temperature.

360 This adaptation is required to maintain activity at temperatures that would denature mesophilic 
361 homologs and is found at all levels of protein structure, from primary through quaternary. Protein

362 thermostability is also not uniform across the proteome and depends on its functional role:

363 proteins either having catalytic activity or regulating other catalytic proteins appear to be under

364 greater selection to be temperature adapted than proteins involved in, for example, core

365 transcriptional or translational processes (Gu and Hilser 2009).

366 While there are many examples of specific thermostabilizing characteristics and

367 interactions at each of the four levels of globular protein structure (reviewed by Imanaka (2011)

368 and Li et al. (2005)), there is no universal property that confers thermostability. Rather, it is the

369 combination of factors at all levels of structure that grants high temperature activity in globular

370 proteins. Increased thermostability is often due to slight differences in sequence and structure, and

371 thermophilic and mesophilic counterparts are typically very similar proteins (Taylor and Vaisman

372 2010). Below we briefly overview known pathways to temperature adaptation in globular proteins.

373 Protein primary structure is the amino acid sequence of the polypeptide chain. Ultimately,

374 the properties and sequence of the amino acids determine the final higher level structures of the

375 protein. One characteristic associated with thermostable proteins is enrichment of amino acids that

376 contribute to a strong hydrophobic core. Larger aliphatic amino acids with more branches are

377 favored at positions that fill cavities, which may ultimately strengthen the protein through

378 increased hydrophobic interactions (Clark et al. 2004). Taylor and Vaisman (2010), however,

379 found that it is only a moderately good indicator of protein thermostability.

380 Comparisons of amino acid composition of thermophilic and mesophilic proteins have

381 revealed several trends at the global proteome level. The observed excess of charged (D,E,K,R)

382 versus polar (N,Q,S,T) amino acids in soluble proteins from hyperthermophiles, known as the

383 CvP bias (Cambillau and Claverie 2000; Gao and Wang 2012; Holder et al. 2013; Suhre and 
384 Claverie 2003), may reflect larger importance of ionic interactions between charged amino acids

385 over hydrogen-bond interactions for retaining protein structure as temperature increases

386 (Cambillau and Claverie 2000). Additionally, a systematic evaluation of all possible subsets of

387 amino acids revealed that the total fraction of the amino acids IVYWREL in a proteome most

388 strongly correlates with optimal growth temperature (Zeldovich et al. 2007).

389 The CvP and IVYWREL biases have been explored thoroughly in the Thermotogae where

390 both indices show strong linear correlations with optimal growth temperature (Zhaxybayeva et al.

391 2009). Specifically, the distribution of CvP values was unimodal for each of the Thermotogae

392 proteomes, arguing against the hypothesis that thermophily is a recently acquired trait of the

393 Thermotogae. Moreover, calculation of CvP values from estimated ancestral Thermotogae

394 sequences suggested that the ancestral Thermotogae proteome belonged to organisms with an

395 optimal growth temperature of $\approx 84.5^{\circ} \mathrm{C}$, higher than that of any characterized extant Thermotogae

396 bacterium (Zhaxybayeva et al. 2009). While the average CvP value for most of the thermophilic

397 Thermotogae lineages was above 10.62, the mesophilic M. prima proteome has an average CvP

398 value of 8.96 (Zhaxybayeva et al. 2012). Also this genome has a unimodal CvP distribution,

399 suggesting it has maintained a mesophilic lifestyle for a long time. An exception to the trend is

400 observed in the P. lettingae genome, which has an average CvP value of 8.42 (Zhaxybayeva et al.

401 2009), but an optimal growth temperature of $65^{\circ} \mathrm{C}$. However, $P$. lettingae-like $16 \mathrm{~S}$ rRNA genes

402 and genomic DNA have been recovered from environments with temperatures $<65^{\circ} \mathrm{C}$ (e.g., $40-$

$40350^{\circ} \mathrm{C}$, (Nesbø et al. 2010; Nobu et al. 2014)), suggesting that these bacteria often live at

404 temperatures below the optimal growth temperature of the cultivated isolate.

405 Protein secondary structure describes the local folding of polypeptide sequences. This

406 includes regular structures like $\alpha$-helices and $\beta$-sheets, or irregular structures like $\beta$-turns, coils 
407 and loops. These are formed primarily by hydrogen bond interactions between the backbone and

408 side chain elements of the amino acids. In addition to having secondary structures that facilitate

409 tighter packing and rigidity at the tertiary level, thermophilic proteins tend to have secondary

410 structures that are more stabilized than their mesophilic counterparts (Facchiano et al. 1998; Koga

411 et al. 2008; Prakash and Jaiswal 2010). For example, thermostable proteins have been reported to

412 have a larger fraction of their amino acid residues arranged in $\alpha$-helices than mesophilic proteins

413 do (Prakash and Jaiswal 2010).

414 Protein tertiary structure is the arrangement of a folded polypeptide chain in three-

415 dimensional space. This is achieved by disulfide bridges, electrostatic interactions within the

416 polypeptide chain, and hydrophobic interactions and hydrogen bonding within the chain as well as

417 between the peptides and solvent. Thermophilic proteins tend to have conformations that are more

418 rigid and more tightly packed, with reduced entropy of unfolding and conformational strain

419 compared to their mesophilic counterparts (Li et al. 2005). The strongest contributors to

420 thermostability are increased ion pairs on the protein surface combined with a more strongly

421 hydrophobic interior (Taylor and Vaisman 2010). In agreement with this, additional salt bridges

422 on the surface of the enzyme diguanylate cyclase from T. maritima accounted for its greater

423 thermostability compared to the same enzyme found in the mesophiles Pseudomonas aeruginosa,

424 Marinobacter aquaeolei and Geobacter sulfurreducens (Deepthi et al. 2014). Additionally, the

425 glutamate dehydrogenase enzymes of the hyperthermophilic bacterium T. maritima and

426 hyperthermophilic archaeon $P$. furiosus have smaller hydrophobic accessible surface area (ASA)

427 and greater charged ASA than the glutamate dehydrogenase from the mesophilic bacterium

428 Clostridium symbiosum (Knapp et al. 1997). Since few other structural differences were found 
429 between the thermophilic and mesophilic enzymes, this tighter packing is thought to contribute to

430 the thermal stability of the proteins.

431 Protein quaternary structure is the arrangement of multiple folded polypeptide chains into

432 a multimeric complex. In globular proteins this level of structure is formed and maintained by

433 many of the same forces that contribute to the tertiary structure of a protein, but between

434 polypeptide chains rather than within them. These forces include disulfide bridges, electrostatic

435 interactions, hydrophobic interactions and hydrogen bonding. In thermostable proteins, greater

436 numbers of these interactions, or stronger interactions over weaker ones, are favored (Li et al.

437 2005).

438 One additional way of achieving greater protein stability is to increase the number of

439 subunits. For example, the malate dehydrogenase (MDH) enzyme, which is usually a dimer in

440 mesophiles, is a tetramer in the thermophilic bacterium Chloroflexus aurantiacus (Bjørk et al.

441 2003). The additional dimer-dimer interface of the tetrameric MDH is hypothesized to provide

442 thermal stability due to the higher number of inter-polypeptide interactions compared to the

443 mesophilic dimers. To test this hypothesis, Bjørk et al. (2003) introduced a disulfide bridge that

444 would strengthen dimer-dimer interaction further, and found that the new enzyme had a melting

445 temperature $15^{\circ} \mathrm{C}$ higher than the wild-type enzyme. In addition, removing excess negative charge

446 at the dimer-dimer interface by replacing a glutamate residue with either glutamine or lysine

447 resulted in an increase of apparent melting temperature by $24^{\circ} \mathrm{C}$ (Bjørk et al. 2004).

449 Tolerating new temperatures: Is it possible to modify just a few proteins?

450 As discussed above, adaptation to a high optimal growth temperature is achieved differently by

451 Bacteria and Archaea, by one species than another, and even by one protein than another within 
452 the same organism. Given that all of these factors combine in unique ways to permit growth

453 within a specific temperature range, how could a shift in permissive temperature range be

454 accomplished? While some of these strategies are universal to thermophiles and mesophiles, such

455 as utilization of chaperones and compatible solutes, others, like shifting of membrane properties,

456 would have to be radically altered to accommodate large changes in temperature range.

457 Changing a few key proteins may have global stabilizing effects on the whole cell. For

458 instance, some of the proteins whose stability appears most affected by thermal adaptation are

459 involved in production of compatible solutes that stabilize other proteins (Gu and Hilser 2009).

460 Such changes would reduce the need to modify the stability of all components of the proteome. It

461 may also be possible to lower the maximal growth temperature of an organism through changes to

462 a single protein (Endo et al. 2006). By replacing the chromosomal copy of groEL chaperonin in

463 Bacillus subtilis 168 (growth range from 11 to $52^{\circ} \mathrm{C}$ ) with a psychrophilic groEL from

464 Pseudoalteromonas sp. PS1M3 (growth range from 4 to $30^{\circ} \mathrm{C}$ ), Endo and colleagues noted a $2^{\circ} \mathrm{C}$

465 reduction in the maximal growth temperature of the newly constructed B. subtilis strain. Similarly,

466 the heterologous expression of a small heat shock protein from Caenorhabditis elegans, enabled $E$.

467 coli cells to grow at temperatures up to $50^{\circ} \mathrm{C}$ (and survive heat shock at $58^{\circ} \mathrm{C}$ for $1 / 2 \mathrm{~h}$ ) extending

468 its growth range by $3.5^{\circ} \mathrm{C}$ (Ezemaduka et al. 2014). While these changes do not constitute true

469 shifts in growth temperature range or changes to optimal growth temperature, these studies

470 suggest that changes to a single key protein (involved both in temperature adaptation and

471 response) could extend or narrow the temperature range at which an organism is able to grow by a

472 few degrees. Accumulation of several such mutations could eventually lead to a more substantial

473 shift in growth range. Some of these mutations may be advantageous at lower temperatures, while

474 others may be loss-of-function mutations, where abilities to function at higher temperatures are 
475 lost for proteins in individuals living in an environment with temperatures at the lower end of

476 their original growth range. Under the latter scenario, change in the growth temperature range

477 might not be a result of selection, but rather a product of random genetic drift or genetic

478 hitchhiking with another, unrelated trait selected for in the new environment.

480 Role of Lateral Gene Transfer in Temperature Adaptation: Acquisition of Already

481 'Adapted' Genes

482 Lateral gene transfer (LGT) is a major force in prokaryotic evolution, allowing rapid adaptation to

483 changes in the environment by acquiring clusters of genes or single genes that confer a selective

484 advantage (Boucher et al. 2003; Zhaxybayeva and Doolittle 2011) and LGT has been implicated

485 in adaptation to extreme environments including high temperatures (see for example Omelchenko

486 et al. (2005)). Genes encoding proteins linked to adaptation to higher or lower growth

487 temperatures have been laterally exchanged (reviewed in Boucher et al. 2003). Reverse gyrase is

488 a classic example of lateral transfer of a single gene that is thought to have been crucial for

489 evolutionary adaptation to high temperatures by hyperthermophilic Bacteria (Brochier-Armanet

490 and Forterre 2006; Forterre 2002). Phylogenetic analyses suggest two ancient acquisitions of this

491 gene by bacterial lineages from Archaea, followed by secondary transfer events among Bacteria

492 (Brochier-Armanet and Forterre 2006).

493 Similarly, the compatible solute di-myo-inositol phosphate is thought to be important for

494 heat tolerance in thermophiles and hyperthermophiles (Borges et al. 2010). Two key genes

495 involved in the synthesis of this compound (inositol-1-phosphate cytidylyltransferase and di-myo-

496 inositol phosphate phosphate synthase) are suggested to have been laterally transferred from an

497 archaeal lineage to hyperthermophilic marine Thermotoga species, while in other lineages the two 
498 genes are predicted to have fused before being exchanged among several bacterial and archaeal

499 lineages (Gonçalves et al. 2012).

$500 \quad$ Reverse gyrase and the myo-inositol pathway genes are just two examples of a large

501 number of genes transferred into the Thermotogae. When the genome of T. maritima MSB8 was

502 first sequenced (Nelson et al. 1999), 24\% of its open reading frames (ORFs) showed greatest

503 similarity to sequences from Archaea, suggesting that these genes have been acquired from these

504 distantly related organisms that inhabit the same environment. Comparative genomic analyses of

505 additional Thermotogae genomes have confirmed an influx of genes from Archaea (albeit the total

506 number dropped to $10-11 \%$ of the ORFs, due to increased number of bacterial homologs in

507 GenBank) and an even larger fraction of Firmicutes genes in these genomes (Mongodin et al.

508 2005; Nesbø et al. 2009; Zhaxybayeva et al. 2009; Zhaxybayeva et al. 2012). Phylogenetic

509 analysis of all the ORFs in the M. prima genome suggests this lineage has undergone extensive

510 gene exchange with diverse mesophilic lineages, and that LGT has aided its transition from a

511 thermophilic to a mesophilic lifestyle (Zhaxybayeva et al. 2012). Thus, as a major force that has

512 shaped the genomes of the Thermotogae, LGT may have also been important for the acquisition

513 and development of the temperature ranges of the various Thermotogae lineages. Most of the

514 acquired genes in Thermotogae (including M. prima) are involved in carbohydrate metabolism

515 (Mongodin et al. 2005; Nesbø et al. 2009; Zhaxybayeva et al. 2009; Zhaxybayeva et al. 2012).

516 However, $M$. prima has additionally acquired genes involved in signal transduction mechanisms,

517 secondary metabolite biosynthesis, and amino acid transport and metabolism (Zhaxybayeva et al.

518 2012), suggesting the potential importance of genes from these functional categories for life at

519 lower temperatures.

520 


\section{Transition to mesophily in Kosmotoga and Mesotoga}

522 The discovery of the mesophilic Thermotogae lineage (Mesotoga) raised the possibility that

523 (hyper)thermophily was not ancestral to the phylum. However, as discussed above, the amino acid

524 composition (CvP bias and IVYWREL amino acids frequency) of the reconstructed ancestral

525 Thermotogae proteome suggests that the ancestral Thermotogae was a hyperthermophile

526 (Zhaxybayeva et al. 2009), and that the transition to mesophily in the Thermotogae phylum is

527 secondary. Moreover, ancestral sequence reconstruction of myo-inositol-3-phosphate synthase

528 enzymes in the Thermotoga genus also suggests that the ancestor of this hyperthermophilic

529 lineage grew optimally at temperatures higher than those of extant species (Butzin et al. 2013).

530 The G+C content of ribosomal RNA, which correlates with optimal growth temperature, also

531 suggests that the reconstructed $16 \mathrm{~S}$ rRNA of the ancestor of all Thermotogae belonged to a

532 thermophile (Green et al. 2013; Zhaxybayeva et al. 2009).

533 So far, the genus Mesotoga is the only strictly mesophilic Thermotogae, with optimal

534 growth occurring between 37 and $45^{\circ} \mathrm{C}$ (Ben Hania et al. 2013; Nesbø et al. 2012). Initially

535 Mesotoga spp. were only detected using molecular tools such as community 16S rRNA PCR and

536 metagenome analyses (Nesbø et al. 2006b). Mesotoga prima was the first described isolate of the

537 genus (Nesbø et al. 2012), which now includes another validated species, Mesotoga infera, (Ben

538 Hania et al. 2013), one yet to be validated, Mesotoga sp. PhosAc3 (Ben Hania et al. 2011), and

539 several isolates with ongoing genome sequencing projects (Benson et al. 2014; Reddy et al.

540 2014). The $2.97 \mathrm{Mb}$ genome of $M$. prima is considerably larger than any previously sequenced

541 Thermotogae genome, which range between 1.86 and 2.30 Mb (Zhaxybayeva et al. 2012). This

542 larger size is due to both higher numbers of protein-coding genes and larger intergenic regions. A

543 unimodal distribution of CvP values of $M$. prima's proteome, with a mean value in the 
544 mesophilic range, indicate that native M. prima proteins have also changed in response to its

545 evolved mesophilic lifestyle (Zhaxybayeva et al. 2012).

$546 \quad$ Analysis of additional Thermotogae shows that the variation in size may be related to

547 optimal growth temperature: thermophiles have more streamlined genomes, with little intergenic

548 space and a higher number of genes per transcription unit, while mesophiles have larger

549 intergenic spaces and higher gene redundancy (Latif et al. 2013; Zhaxybayeva et al. 2012). This

550 finding holds true for lineages outside of the Thermotogae, as examination of 1155 prokaryotes

551 demonstrates (Sabath et al. 2013). However, the observed correlation in Thermotogae needs to

552 be untangled from effects of phylogenetic history (Zhaxybayeva et al. 2012).

553 The closest relative of the Mesotoga lineage is the thermophilic lineage Kosmotoga (Fig.

554 3). Members of this genus have been found in hydrothermal sediments (L'Haridon et al. 2014;

555 Nunoura et al. 2010) and oil production fluids (DiPippo et al. 2009; Feng et al. 2010). Like other

556 thermophilic Thermotogae, the Kosmotoga are anaerobic chemoorganotrophs able to ferment

557 carbohydrates and peptides (Nunoura et al. 2010) and to produce molecular hydrogen (DiPippo

558 et al. 2009; Feng et al. 2010). The first isolated bacterium of this genus was Kosmotoga olearia

559 (DiPippo et al. 2009). K. olearia grows optimally at $65^{\circ} \mathrm{C}$ and has a reported growth range of 20-

$56080^{\circ} \mathrm{C}$ (DiPippo et al. 2009). Not only is this bacterium capable of growing at an unusually low

561 temperature for a thermophile, but to our knowledge it represents the widest reported bacterial

562 temperature growth range to date.

563 The ability of Kosmotoga to grow at such an extraordinary gamut of temperatures is

564 intriguing for two reasons. First, it must maintain protein activity and membrane integrity. Every

565 living organism has adapted to do this at a certain temperature range, but how these requirements

566 can be maintained over a $60^{\circ} \mathrm{C}$ range is unknown. What evolutionary mechanisms would maintain 
567 a $60^{\circ} \mathrm{C}$ growth interval in Kosmotoga? Perhaps this lineage continues to experience environments

568 with more variable temperatures or, alternatively, the wide growth range may be a result of

569 selection on another trait. Second, as discussed above, this ability of tolerating a wide range of

570 temperature conditions, may have facilitated the transition of Mesotoga from thermophily to

571 mesophily, because the capacity to grow at lower temperatures presumably already existed in

572 Mesotoga's ancestors.

573 As a result Kosmotoga and Mesotoga offer a unique model system for studying both

574 immediate temperature responses and long-term temperature adaptation. Specifically, K. olearia's

575 exceptionally wide growth range allows examination of temperature responses under both

576 mesothermic and thermic conditions in the same cell-line. For example, analysis of K. olearia's

577 transcriptome at different growth temperatures promises to shed light into the role of specific

578 processes, functions, genes or proteins in thermoadaptation. Since K. olearia's closest relative is a

579 mesophile with a narrower growth range, comparative genomic, transcriptomic and proteomic

580 analyses promise to reveal how Kosmotoga's temperature responses may eventually lead to

581 temperature adaptation. If we assume that Mesotoga and Kosmotoga's common ancestor was a

582 thermophile, possibly with a wide growth range, then the Mesotoga lineage lost its ability to grow

583 at high temperatures, while Kosmotoga has either kept or expanded its growth range. For

584 Mesotoga we have speculated that reduction of its growth temperature range may have happened

585 as the lineage got 'trapped' in an oil reservoir that cooled down (Nesbø et al. 2006b; Zhaxybayeva

586 et al. 2012) and therefore may be a result of loss-of-function mutations and genetic drift.

587 The existence of several additional Thermotogae lineages likely thriving in mesothermic

588 environments (Nesbø et al. 2010) opens opportunities to study the evolutionary processes in

589 lineages that have adapted to lower temperatures independently. These novel lineages can be 
590 accessed through metagenomic studies or through further cultivation efforts. Taken together,

591 future genomic, transcriptomic and proteomic studies of temperature responses and adaptations

592 in Kosmotoga, Mesotoga, and other Thermotogae will help decipher how shifts in temperature

593 range and optimum are accomplished.

594

595 Acknowledgements

596 This work is supported by an NSERC Alexander Graham Bell Canada Graduate Scholarship

597 CGS-M to S.M.J.P., by a Norwegian Research Council of Norway award (project no.

598 180444/V40) to C.L.N., and by a Simons Investigator award from the Simons Foundation,

599 Dartmouth's Walter and Constance Burke Research Initiation Award and Dean of Faculty start-

600 up funds to O.Z.

601

602

\section{References}

603

604 Achenbach-Richter, L., Gupta, R., Stetter, K.O., and Woese, C.R. 1987. Were the original

605 eubacteria thermophiles? Syst. Appl. Microbiol. 9(1-2): 34-39.

606 Adl, S.M., Simpson, A.G.B., Lane, C.E., Lukeš Julius, Bass, D., Bowser, S.S. et al. 2012. The

607 revised classification of eukaryotes. J. Eukaryot. Microbiol. 59(5): 429-493.

608 Akanuma, S., Nakajima, Y., Yokobori, S., Kimura, M., Nemoto, N., Mase, T., et al. 2013.

609 Experimental evidence for the thermophilicity of ancestral life. Proc. Natl. Acad. Sci. U. S. A.

610 110(27): 11067-11072.

611 Arti, D., Park, J., Jung, T.Y., Song, H., Jang, M., Han, N.S. et al. 2012. Structural analysis of $\alpha$ 612 L-Arabinofuranosidase from Thermotoga maritima reveals characteristics for thermostability and 613 substrate specificity. J.Microbiol.Biotechnol. 22(12): 1724-1730.

614 Atomi, H., Matsumi, R., and Imanaka, T. 2004. Reverse gyrase is not a prerequisite for 615 hyperthermophilic life. J. Bacteriol. 186(14): 4829-4833. 
616 Ben Hania, W., Ghodbane, R., Postec, A., Brochier-Armanet, C., Hamdi, M., Fardeau, M. et al. 617 2011. Cultivation of the first mesophilic representative (mesotoga) within the order

618 Thermotogales. Syst. Appl. Microbiol. 34(8): 581-585.

619 Ben Hania, W., Postec, A., Aüllo, T., Ranchou-Peyruse, A., Erauso, G., Brochier-Armanet, et al. 620 2013. Mesotoga infera sp. nov., a mesophilic member of the order Thermotogales, isolated from 621 an underground gas storage aquifer. Int. J. Syst. Evol. Microbiol. 63: 3003-3008.

622 Benson, D.A., Clark, K., Karsch-Mizrachi, I., Lipman, D.J., Ostell, J., and Sayers, E.W. 2014. 623 GenBank. Nucleic Acids Res. 43: D30-D35.

624 Bhandari, V., and Gupta, R.S. 2014. Molecular signatures for the phylum (class) Thermotogae 625 and a proposal for its division into three orders (Thermotogales, Kosmotogales ord. nov. and 626 Petrotogales ord. nov.) containing four families (Thermotogaceae, Fervidobacteriaceae fam. 627 nov., Kosmotogaceae fam. nov. and Petrotogaceae fam. nov.) and a new 628 genus Pseudothermotoga gen. nov. with five new combinations. Antonie van Leeuwenhoek 629 105(1): 143-168.

630 Bjørk, A., Dalhus, B., Mantzilas, D., Sirevåg, R., and Eijsink, V.G.H. 2004. Large improvement 631 in the thermal stability of a tetrameric malate dehydrogenase by single point mutations at the 632 dimer-dimer interface. J. Mol. Biol. 341(5): 1215-1226.

633 Bjørk, A., Dalhus, B., Mantzilas, D., Eijsink, V.G.H., and Sirevåg, R. 2003. Stabilization of a 634 tetrameric malate dehydrogenase by introduction of a disulfide bridge at the dimer-dimer 635 interface. J. Mol. Biol. 334(4): 811-821.

636 Borges, N., Matsumi, R., Imanaka, T., Atomi, H., and Santos, H. 2010. Thermococcus 637 kodakarensis mutants deficient in di-myo-inositol phosphate use aspartate to cope with heat 638 stress. J. Bacteriol. 192(1): 191-197.

639 Boucher, N., and Noll, K.M. 2011. Ligands of thermophilic ABC transporters encoded in a 640 newly sequenced genomic region of Thermotoga maritima MSB8 screened by differential 641 scanning fluorimetry. Appl. Environ. Microbiol. 77(18): 6395-6399.

642 Boucher, Y., Douady, C.J., Papke, R.T., Walsh, D.A., Boudreau, M.E.R., Nesbø, C.L., et al. 643 2003. Lateral gene transfer and the origins of prokaryotaic groups. Annu. Rev. Genet. 37: 283644328.

645 Boussau, B., Blanquart, S., Necsulea, A., Lartillot, N., and Gouy, M. 2008. Parallel adaptations 646 to high temperatures in the Archaean eon. Nature 456(7224): 942-945.

647 Brochier-Armanet, C., and Forterre, P. 2006. Widespread distribution of archaeal reverse gyrase 648 in thermophilic bacteria suggests a complex history of vertical inheritance and lateral gene 649 transfers. Archaea 2(2): 83-93. 
650 Butzin, N.C., Lapierre, P., Green, A.G., Swithers, K.S., Gogarten, J.P., and Noll, K.M. 2013. 651 Reconstructed Ancestral Myo-Inositol-3-Phosphate Synthases Indicate That Ancestors of the 652 Thermococcales and Thermotoga Species Were More Thermophilic than Their Descendants. 653 PloS one 8(12): e84300.

654 Cambillau, C., and Claverie, J. 2000. Structural and genomic correlates of hyperthermostability. 655 The Journal of biological chemistry 275(42): 32383-32386.

656 Canaves, J.M. 2004. Predicted role for the Archease protein family based on structural and 657 sequence analysis of TM1083 and MTH1598, two proteins structurally characterized through 658 structural genomics efforts. Proteins 56(1): 19-27.

659 Cappelletti, M., Zannoni, D., Postec, A., and Ollivier, B. 2014. Members of the order 660 Thermotogales: From microbiology to hydrogen production. In Microbial BioEnergy: Hydrogen 661 Production. Edited by D. Zannoni and R. De Philippis. Springer Netherlands, Dordrecht. pp. 197662224.

663 Carballeira, N.M., Reyes, M., Sostre, A., Huang, H., Verhagen, M.F., and Adams, M.W. 1997. 664 Unusual fatty acid compositions of the hyperthermophilic archaeon Pyrococcus furiosus and the 665 bacterium Thermotoga maritima. J. Bacteriol. 179(8): 2766-2768.

666 Chang, E.L. 1994. Unusual thermal stability of liposomes made from bipolar tetraether lipids. 667 Biochem. Biophys. Res. Commun. 202(2): 673-679.

668 Chhabra, S.R., Shockley, K.R., Ward, D.E., and Kelly, R.M. 2002. Regulation of endo-acting 669 glycosyl hydrolases in the hyperthermophilic bacterium Thermotoga maritima grown on glucan670 and mannan-based polysaccharides. Appl. Environ. Microbiol. 68: 545-554.

671 Chhabra, S.R., Shockley, K.R., Conners, S.B., Scott, K.L., Wolfinger, R.D., and Kelly, R.M. 672 2003. Carbohydrate-induced differential gene expression patterns in the hyperthermophilic 673 bacterium Thermotoga maritima. J. Biol. Chem. 278(9): 7540-7552.

674 Clark, A.T., McCrary, B.S., Edmondson, S.P., and Shriver, J.W. 2004. Thermodynamics of core 675 hydrophobicity and packing in the hyperthermophile proteins Sac7d and Sso7d. Biochemistry 676 43: 2840-2853.

677 Cobucci-Ponzano, B., Zorzetti, C., Strazzulli, A., Carillo, S., Bedini, E., Corsaro, M.M. et al. 678 2011. A novel $\alpha$-D-galactosynthase from Thermotoga maritima converts $\beta$-D-galactopyranosyl 679 azide to $\alpha$-galacto-oligosaccharides. Glycobiology 21(4): 448-456.

680 Comfort, D.A., Bobrov, K.S., Ivanen, D.R., Shabalin, K.A., Harris, J.M., Kulminskaya, A.A. et 681 al. 2007. Biochemical analysis of Thermotoga maritima GH36 $\alpha$-galactosidase (TmGalA) 682 confirms the mechanistic commonality of clan GH-D glycoside hydrolases. Biochemistry 683 46(11): 3319-3330. 
684 Conners, S.B., Mongodin, E.F., Johnson, M.R., Montero, C.I., Nelson, K.E., and Kelly, R.M. 685 2006. Microbial biochemistry, physiology, and biotechnology of hyperthermophilic Thermotoga 686 species. FEMS Microbiol. Rev. 30(6): 872-905.

687 Cuneo, M.J., Beese, L.S., and Hellinga, H.W. 2009. Structural analysis of semi-specific 688 oligosaccharide recognition by a cellulose-binding protein of Thermotoga maritima reveals 689 adaptations for functional diversification of the oligopeptide periplasmic binding protein fold. J. 690 Biol. Chem. 284(48): 33217-33223.

691 Dagan, T., Roettger, M., Bryant, D., and Martin, W. 2010. Genome networks root the tree of life 692 between prokaryotic domains. Genome Biology and Evolution 2: 379-392.

693 Dahle, H., Hannisdal, B., Steinsbu, B.O., Ommedal, H., Einen, J., Jensen, et al. 2011. Evolution 694 of temperature optimum in Thermotogaceae and the prediction of trait values of uncultured 695 organisms. Extremophiles 15(4): 509-516.

696 Damsté, J.S.S., Rijpstra, W.I.C., Hopmans, E.C., Schouten, S., Balk, M., and Stams, A.J.M. 697 2007. Structural characterization of diabolic acid-based tetraester, tetraether and mixed 698 ether/ester, membrane-spanning lipids of bacteria from the order Thermotogales. Arch. 699 Microbiol. 188(6): 629-641.

700 de Mendoza, D. 2014. Temperature sensing by membranes. Annu. Rev. Microbiol. 68: 101-116.

701 Deepthi, A., Liew, C.W., Liang, Z., Swaminathan, K., and Lescar, J. 2014. Structure of a 702 diguanylate cyclase from Thermotoga maritima: Insights into activation, feedback inhibition and 703 thermostability. PloS one 9(10): e110912.

704 DiDonato, M., Deacon, A.M., Klock, H.E., McMullan, D., and Lesley, S.A. 2004. A scaleable 705 and integrated crystallization pipeline applied to mining the Thermotoga maritima proteome. J.

706 Struct. Funct. Genomics 5: 133-146.

707 DiPippo, J.L., Nesbø, C.L., Dahle, H., Doolittle, W.F., Birkland, N., and Noll, K.M. 2009. 708 Kosmotoga olearia gen. nov., sp. nov., a thermophilic, anaerobic heterotroph isolated from an oil 709 production fluid. Int. J. Syst. Evol. Microbiol. 59: 2991-3000.

710 D'Ippolito, G., Dipasquale, L., and Fontana, A. 2014. Recycling of carbon dioxide and acetate as 711 lactic acid by the hydrogen-producing bacterium Thermotoga neapolitana. ChemSusChem 7: $712 \quad 2678-2683$.

713 DiRuggiero, J., Santangelo, N., Nackerdien, Z., Ravel, J., and Robb, F.T. 1997. Repair of 714 extensive ionizing-radiation DNA damage at 95 degrees $\mathrm{C}$ in the hyperthermophilic archaeon 715 Pyrococcus furiosus. J. Bacteriol. 179(14): 4643-4645.

716 Doerrler, W.T., Sikdar, R., Kumar, S., and Boughner, L.A. 2013. New functions for the ancient 717 DedA membrane protein family. J. Bacteriol. 195(1): 3-11. 
Endo, A., Sasaki, M., Maruyama, A., and Kurusu, Y. 2006. Temperature adaptation of Bacillus subtilis by chromosomal groEL replacement. Biosci. Biotechnol. Biochem. 70(10): 2357-2362.

720 Ezemaduka, A.N., Yu, J., Shi, X., Zhang, K., Yin, C., Fu, X. et al. 2014. A small heat shock protein enables Escherichia coli to grow at a lethal temperature of $50^{\circ} \mathrm{C}$ conceivably by maintaining cell envelope integrity. J. Bacteriol. 196(11): 2004-2011. Facchiano, A., Colonna, G., and Ragone, R. 1998. Helix-stabilizing factors and stabilization of thermophilic proteins: an X-ray based study. Protein Eng. 11(9): 753-760.

Feng, Y., Cheng, L., Zhang, X., Li, X., Deng, Y., and Zhang, H. 2010. Thermococcoides shengliensis gen. nov., sp. nov., a new member of the order Thermotogales isolated from oilproduction fluid. Int. J. Syst. Evol. Microbiol. 60: 932-937.

Forterre, P., Bouthier De La Tour C, Philippe, H., and Duguet, M. 2000. Reverse gyrase from hyperthermophiles: probable transfer of a thermoadaptation trait from Archaea to Bacteria.

730 Trends in genetics : TIG 16(4): 152-154.

731 Forterre, P. 2002. A hot story from comparative genomics: reverse gyrase is the only 732 hyperthermophile-specific protein. Trends in genetics : TIG 18(5): 236-237.

733 Frock, A.D., Gray, S.R., and Kelly, R.M. 2012. Hyperthermophilic Thermotoga species differ with respect to specific carbohydrate transporters and glycoside hydrolases. Appl. Environ. Microbiol. 78(6): 1978-1986.

Galtier, N., and Lobry, J.R. 1997. Relationships between genomic G+C content, RNA secondary structures, and optimal growth temperature in prokaryotes. J. Mol. Evol. 44(6): 632-636.

738 Gao, J., and Wang, W. 2012. Analysis of structural requirements for thermo-adaptation from 739 orthologs in microbial genomes. Annals of Microbiology 62(4): 1635-1641.

740 Ghimire-Rijal, S., Lu, X., Myles, D.A., and Cuneo, M.J. 2014. Duplication of genes in an ATPbinding cassette transport system increases dynamic range while maintaining ligand specificity.

742 J. Biol. Chem. 289(43): 30090-30100.

743 Godin-Roulling, A., Schmidpeter, P.A.M., Schmid, F.X., and Feller, G. 2014. Functional 744 adaptations of the bacterial chaperone trigger factor to extreme environmental temperatures. 745 Environ. Microbiol. in press.

746 Gogarten, J.P., Kibak, H., Dittrich, P., Taiz, L., Bowman, E.J., Bowman, et al. 1989. Evolution of the vacuolar H+-ATPase: implications for the origin of eukaryotes. Proc. Natl. Acad. Sci. U.

748 S. A. 86(September): 6661-6665.

749 Gonçalves, L.G., Borges, N., Serra, F., Fernandes, P.L., Dopazo, H., and Santos, H. 2012.

750 Evolution of the biosynthesis of di-myo-inositol phosphate, a marker of adaptation to hot marine 751 environments. Environ. Microbiol. 14(3): 691-701. 
752 Green, A.G., Swithers, K.S., Gogarten, J.F., and Gogarten, J.P. 2013. Reconstruction of ancestral 753 16S rRNA reveals mutation bias in the evolution of optimal growth temperature in the

754 Thermotogae phylum. Mol. Biol. Evol. 30(11): 2463-2474.

755 Gu, J., and Hilser, V.J. 2009. Sequence-based analysis of protein energy landscapes reveals nonuniform thermal adaptation within the proteome. Mol. Biol. Evol. 26(10): 2217-2227.

757 Higashibata, H., Fujiwara, S., Takagi, M., and Imanaka, T. 1999. Analysis of DNA compaction 758 profile and intracellular contents of archaeal histones from Pyrococcus kodakaraensis KOD1.

759 Biochem. Biophys. Res. Commun. 258(2): 416-424.

760 Higashibata, H., Fujiwara, S., Ezaki, S., Takagi, M., Fukui, K., and Imanaka, T. 2000. Effect of polyamines on histone-induced DNA compaction of hyperthermophilic Archaea. J. Biosci. Bioeng. 89(1): 103-106.

763 Hobbs, J.K., Shepherd, C., Saul, D.J., Demetras, N.J., Haaning, S., Monk, C.R., et al. 2012. On 764 the origin and evolution of thermophily: Reconstruction of functional precambrian enzymes from 765 ancestors of Bacillus. Mol. Biol. Evol. 29(2): 825-835.

766 Holder, T., Basquin, C., Ebert, J., Randel, N., Jollivet, D., Conti, E. et al. 2013. Deep

767 transcriptome-sequencing and proteome analysis of the hydrothermal vent annelid Alvinella 768 pompejana identifies the CvP-bias as a robust measure of eukaryotic thermostability. Biology 769 direct 8(2): 1-16.

770 Huber, R., and Hannig, M. 2006. Thermotogales. In The Prokaryotes. Edited by M. Dworkin, S. 771 Falkow, E. Rosenberg, K. Schleifer, Stackebr and E. t. Springer New York pp. 899-922.

772 Huber, R., Langworthy, T.A., König, H., Thomm, M., Woese, C.R., Sleytr, U.B., and Stetter, 773 K.O. 1986. Thermotoga maritima sp. nov. represents a new genus of unique extremely 774 thermophilic eubacteria growing up to $90^{\circ} \mathrm{C}$. Arch. Microbiol. 144: 324-333.

775 Hurst, L.D., and Merchant, A.R. 2001. High guanine-cytosine content is not an adaptation to high temperature: a comparative analysis amongst prokaryotes. Proc. R. Soc. Lond. B 268(1466): 493-497.

778 Imanaka, T. 2011. Molecular bases of thermophily in hyperthermophiles. Proc. Japan Acad. , 779 Ser. B 87(9): 587-602.

780 Iwabe, N., Kuma, K., Hasegawa, M., Osawa, S., and Miyata, T. 1989. Evolutionary relationship 781 of archaebacteria, eubacteria, and eukaryotes inferred from phylogenetic trees of duplicated 782 genes. Proc. Natl. Acad. Sci. U. S. A. 86(December): 9355-9359.

783 Johnston, C., Martin, B., Fichant, G., Polard, P., and Claverys, J. 2014. Bacterial transformation: 784 distribution, shared mechanisms and divergent control. Nature reviews.Microbiology 12: 181785196. 
Jolivet, E., Matsunaga, F., Ishino, Y., Forterre, P., Prieur, D., and Myllykallio, H. 2003. Physiological responses of the hyperthermophilic archaeon "Pyrococcus abyssi" to DNA damage caused by ionizing radiation. J. Bacteriol. 185(13): 3958-3961.

Jorge, C.D., Lamosa, P., and Santos, H. 2007. Alpha-D-mannopyranosyl-(1->2)-alpha-Dglucopyranosyl-(1->2)-glycerate in the thermophilic bacterium Petrotoga miotherma - structure, cellular content and function. FEBS J. 274(12): 3120-3127.

792 Kimura, H., Mori, K., Yamanaka, T., and Ishibashi, J. 2013. Growth temperatures of archaeal 793 communities can be estimated from the guanine-plus-cytosine contents of 16S rRNA gene

794 fragments. Environ. Microbiol. Rep. 5(3): 468-474.

795 Kleine, J., and Liebl, W. 2006. Comparative characterization of deletion derivatives of the 796 modular xylanase XynA of Thermotoga maritima. Extremophiles 10: 373-381.

797 Knapp, S., Vos, W.M.D., Rice, D., and Ladenstein, R. 1997. Crystal structure of glutamate 798 dehydrogenase from the hyperthermophilic eubacterium Thermotoga maritima at 3.0

799 Å resolution. J. Mol. Biol. 267: 916-932.

800 Koga, Y. 2012. Thermal adaptation of the archaeal and bacterial lipid membranes. Archaea : 801 doi:10.1155/2012/789652.

802 Koga, Y., and Morii, H. 2005. Recent advances in structural research on ether lipids from 803 Archaea including comparative and physiological aspects. Biosci. Biotechnol. Biochem. 69(11): 804 2019-2034.

805 Koga, Y., Katsumi, R., You, D., Matsumura, H., Takano, K., and Kanaya, S. 2008. Crystal 806 structure of highly thermostable glycerol kinase from a hyperthermophilic archaeon in a dimeric 807 form. FEBS J. 275(10): 2632-2643.

808 Konstantinidis, K.T., and Tiedje, J.M. 2005. Towards a genome-based taxonomy for 809 prokaryotes. J. Bacteriol. 187(18): 6258-6264.

810 Large, A.T., Goldberg, M.D., and Lund, P.A. 2009. Chaperones and protein folding in the 811 Archaea. Biochem. Soc. Trans. 37: 46-51.

812 Latif, H., Lerman, J.A., Portnoy, V.A., Tarasova, Y., Nagarajan, H., Schrimpe-Rutledge, A.C., 813 Smith, R.D., Adkins, J.N., Lee, D., Qiu, Y., and Zengler, K. 2013. The genome organization of 814 Thermotoga maritima reflects its lifestyle. PLoS genetics 9(4): e1003485.

815 Lesley, S.A., Kuhn, P., Godzik, A., Deacon, A.M., Mathews, I., Kreusch, A. et al. 2002.

816 Structural genomics of the Thermotoga maritima proteome implemented in a high-throughput 817 structure determination pipeline. Proc. Natl. Acad. Sci. U. S. A. 99(18): 11664-11669. 
818 L'Haridon, S., Jiang, L., Alain, K., Chalopin, M., Rouxel, O., Beauverger, M., Xu, H., Shao, Z., 819 and Jebbar, M. 2014. Kosmotoga pacifica sp. nov., a thermophilic chemoorganoheterotrophic 820 bacterium isolated from an East Pacific hydrothermal sediment. Extremophiles 18(1): 81-88.

821 Li, W.F., Zhou, X.X., and Lu, P. 2005. Structural features of thermozymes. Biotechnol. Adv. 822 23(4): 271-281.

823 Liu, B., Zhang, Y., and Zhang, W. 2014. RNA-seq-based analysis of cold shock response in 824 Thermoanaerobacter tengcongensis, a bacterium harboring a single cold shock protein encoding 825 gene. PLoS ONE 9(3): e93289.

826 López-García, P. 1999. DNA supercoiling and temperature adaptation: A clue to early 827 diversification of life? J. Mol. Evol. 49: 439-452.

828 Lulchev, P., and Klostermeier, D. 2014. Reverse gyrase - Recent advances and current 829 mechanistic understanding of positive DNA supercoiling. Nucleic Acids Res. 42(13): 82008308213.

831 Mansilla, M.C., Cybulski, L.E., Albanesi, D., and Mendoza, D.D. 2004. Control of membrane 832 lipid fluidity by molecular thermosensors. J. Bacteriol. 186(20): 6681-6688.

833 Markowitz, V.M., Chen, I.A., Palaniappan, K., Chu, K., Szeto, E., Pillay, M. et al. 2014. IMG 4 834 version of the integrated microbial genomes comparative analysis system. Nucleic Acids Res. 835 42: D560-7.

836 Maru, B.T., Bielen, A.A.M., Kengen, S.W.M., Constantí M., and Medinaa, F. 2012.

837 Biohydrogen production from glycerol using Thermotoga spp. Energy Procedia 29: 300-307.

838 McCloskey, J.A., Graham, D.E., Zhou, S., Crain, P.F., Ibba, M., Konisky, J. et al. 2001. Post839 transcriptional modification in archaeal tRNAs: identities and phylogenetic relations of 840 nucleotides from mesophilic and hyperthermophilic Methanococcales. Nucleic Acids Res. 841 29(22): 4699-4706.

842 Mikulik, K., and Anderova, M. 1994. Role of polyamines in the binding of initiator tRNA to the 84370 S ribosomes of extreme thermophilic bacterium Calderobacterium hydrogenophilum. Arch. 844 Microbiol. 161: 508-513.

845 Mino, S., Makita, H., Toki, T., Miyazaki, J., Kato, S., Watanabe, H. et al. 2013. Biogeography of 846 Persephonella in deep-sea hydrothermal vents of the western pacific. Frontiers in Microbiology 847 4: 1-12.

848 Mongodin, E.F., Hance, I.R., DeBoy, R.T., Gill, S.R., Daugherty, S., Huber, R. et al. 2005. Gene 849 transfer and genome plasticity in Thermotoga maritima, a model hyperthermophilic species. J.

850 Bacteriol. 187(14): 4935-4944. 
851 Mukherjee, A., Sokunbi, A.O., and Grove, A. 2008. DNA protection by histone-like protein HU 852 from the hyperthermophilic eubacterium Thermotoga maritima. Nucleic Acids Res. 36(12):

853 3956-3968.

854 Munoz, R., Yarza, P., Ludwig, W., Euzéby, J., Amann, R., Schleifer, K.H. et al. 2011. Release

855 LTPs104 of the All-Species Living Tree. Syst. Appl. Microbiol. 34(January): 169-170.

856 Nanavati, D.M., Thirangoon, K., and Noll, K.M. 2006. Several archaeal homologs of putative 857 oligopeptide-binding proteins encoded by Thermotoga maritima bind sugars. Appl. Environ.

858 Microbiol. 72(2): 1336-1345.

859 Nanavati, D.M., Nguyen, T.N., and Noll, K.M. 2005. Substrate specificities and expression 860 patterns reflect the evolutionary divergence of maltose ABC transporters in Thermotoga 861 maritima. J. Bacteriol. 187(6): 2002-2009.

862 Nelson, K.E., Clayton, R.A., Gill, S.R., Gwinn, M.L., Dodson, R.J., Haft, D.H. et al. 1999. 863 Evidence for lateral gene transfer between Archaea and Bacteria from genome sequence of 864 Thermotoga maritima. Nature 399(6734): 323-329.

865 Nesbø, C.L., Dlutek, M., and Doolittle, W.F. 2006a. Recombination in Thermotoga: Implications 866 for species concepts and biogeography. Genetics 172: 759-769.

867 Nesbø, C.L., Dlutek, M., Zhaxybayeva, O., and Doolittle, W.F. 2006b. Evidence for existence of 868 Mesotogas, members of the order Thermotogales adapted to low-temperature environments.

869 Appl. Environ. Microbiol. 72(7): 5061-5068.

870 Nesbø, C.L., Kumaraswamy, R., Dlutek, M., Doolittle, W.F., and Foght, J. 2010. Searching for 871 mesophilic Thermotogales bacteria: "Mesotogas" in the wild. Appl. Environ. Microbiol. 76(14): 872 4896-4900.

873 Nesbø, C.L., Swithers, K.S., Dahle, H., Haverkamp, T.H., Birkeland, N., Sokolova, T. et al. 874 2014. Evidence for extensive gene flow and Thermotoga subpopulations in subsurface and 875 marine environments. The ISME Journal : 1-11.

876 Nesbø, C.L., Bradnan, D.M., Adebusuyi, A., Dlutek, M., Petrus, A.K., Foght, J., Doolittle, W.F., 877 and Noll, K.M. 2012. Mesotoga prima gen. nov., sp. nov., the first described mesophilic species 878 of the Thermotogales. Extremophiles 16(3): 387-393.

879 Nesbø, C.L., Bapteste, E., Curtis, B., Dahle, H., Lopez, P., Macleod, D. et al. 2009. The genome 880 of Thermosipho africanus TCF52B: lateral genetic connections to the Firmicutes and Archaea. J. 881 Bacteriol. 191(6): 1974-1978.

882 Nguyen, T.A.D., Kim, J.P., Kim, M.S., Oh, Y.K., and Sim, S.J. 2008. Optimization of hydrogen 883 production by hyperthermophilic eubacteria, Thermotoga maritima and Thermotoga neapolitana 884 in batch fermentation. Int J Hydrogen Energy 33: 1483-1488. 

the polyamines caldopentamine and homocaldopentamine in axenic cultures of the red tide flagellates Chattonella antiqua and Heterosigma akashiwo (Raphidophyceae). FEMS Microbiol. Lett. 298(1): 74-78.

889 Nobu, M.K., Narihiro, T., Rinke, C., Kamagata, Y., Tringe, S.G., Woyke, T. et al. 2014.

890 Microbial dark matter ecogenomics reveals complex synergistic networks in a methanogenic 891 bioreactor. The ISME Journal : 1-13.

892 Nogales, J., Gudmundsson, S., and Thiele, I. 2012. An in silico re-design of the metabolism in 893 Thermotoga maritima for increased biohydrogen production. Int J Hydrogen Energy 37(17):

894 12205-12218.

895 Nunoura, T., Hirai, M., Imachi, H., Miyazaki, M., Makita, H., Hirayama, H., et al. 2010. Kosmotoga arenicorallina sp. nov. a thermophilic and obligately anaerobic heterotroph isolated from a shallow hydrothermal system occurring within a coral reef, southern part of the Yaeyama Archipelago, Japan, reclassification of Thermococcoides shengliensis as Kosmotoga shengliensis comb. nov., and emended description of the genus Kosmotoga. Arch. Microbiol. 900 192(10): 811-819.

901 Oger, P.M., and Cario, A. 2013. Adaptation of the membrane in Archaea. Biophys. Chem. 183: 902 42-56.

903 Ollivier, B., and Cayol, J. 2005. Fermentative, iron-reducing, and nitrate-reducing microorganisms. In Petroleum Microbiology. Edited by B. Ollivier and M. Magot. ASM Press, 905 Washington, DC. pp. 71-88.

Omelchenko, M.V., Wolf, Y.I., Gaidamakova, E.K., Matrosova, V.Y., Vasilenko, A., Zhai, M., et al. 2005. Comparative genomics of Thermus thermophilus and Deinococcus radiodurans: divergent routes of adaptation to thermophily and radiation resistance. BMC evolutionary biology 5: 57.

910 Oshima, T., Moriya, T., and Terui, Y. 2011. Identification, chemical synthesis, and biological functions of unusual polyamines produced by extreme thermophiles. Methods Mol. Biol. 720:

912 81-111.

913 Pace, N.R. 1991. Origin of life- Facing up to the physical setting. Cell 65: 531-533.

914 Perugino, G., Valenti, A., D'Amaro, A., Rossi, M., and Ciaramella, M. 2009. Reverse gyrase and 915 genome stability in hyperthermophilic organisms. Biochem. Soc. Trans. 37: 69-73.

916 Pikuta, E.V., Hoover, R.B., and Tang, J. 2007. Microbial extremophiles at the limits of life. Crit. 917 Rev. Microbiol. 33(3): 183-209.

918 Prakash, O., and Jaiswal, N. 2010. Alpha-amylase: An ideal representative of thermostable 919 enzymes. Appl. Biochem. Biotechnol. 160(8): 2401-2414. 
920 Puigbò, P., Pasamontes, A., and Garcia-Vallve, S. 2008. Gaining and losing the thermophilic 921 adaptation in prokaryotes. Trends in Genetics 24(1): 10-14.

922 Pysz, M.A., Ward, D.E., Shockley, K.R., Montero, C.I., Conners, S.B., Johnson, M.R. et al. 923 2004. Transcriptional analysis of dynamic heat-shock response by the hyperthermophilic 924 bacterium Thermotoga maritima. Extremophiles 8(3): 209-217.

925 Reddy, T.B.K., Thomas, A.D., Stamatis, D., Bertsch, J., Isbandi, M., Jansson, J. et al. 2014. The 926 Genomes OnLine Database (GOLD) v.5: a metadata management system based on a four level

927 (meta)genome project classification. Nucleic Acids Res. 43: D1099-D1106.

928 Richter, K., Haslbeck, M., and Buchner, J. 2010. The Heat Shock Response: Life on the Verge of 929 Death. Mol. Cell 40(2): 253-266.

930 Rodionov, D.A., Rodionova, I.A., Li, X., Ravcheev, D.A., Tarasova, Y., Portnoy, V.A. et al. 931 2013. Transcriptional regulation of the carbohydrate utilization network in Thermotoga 932 maritima. Front. Microbiol. 4: 244.

933 Rodionova, I.A., Leyn, S.A., Burkart, M.D., Boucher, N., Noll, K.M., Osterman, A.L. et al. 934 2013. Novel inositol catabolic pathway in Thermotoga maritima. Environ. Microbiol. 15(8): $9352254-2266$.

936 Rodrigues, M.V., Borges, N., Almeida, C.P., Lamosa, P., and Santos, H. 2009. A unique beta937 1,2-mannosyltransferase of Thermotoga maritima that uses di-myo-inositol phosphate as the 938 mannosyl acceptor. J. Bacteriol. 191(19): 6105-6115.

939 Rothschild, L.J., and Mancinelli, R.L. 2001. Life in extreme environments. Nature 409(6823): 940 1092-1101.

941 Sabath, N., Ferrada, E., Barve, A., and Wagner, A. 2013. Growth temperature and genome size 942 in bacteria are negatively correlated, suggesting genomic streamlining during thermal adaptation. 943 Genome Biology and Evolution 5(5): 966-977.

944 Santos, H., Lamosa, P., Borges, N., Gonçalves, L.G., Pais, T., and Rodrigues, M.V. 2011.

945 Organic compatible solutes of prokaryotes that thrive in hot environments: The importance of 946 ionic compounds for thermostabilization. In Extremophiles Handbook. Edited by K. Horikoshi. 947 Springer Japan, Tokyo. pp. 498-516.

948 Schloss, P.D., Westcott, S.L., Ryabin, T., Hall, J.R., Hartmann, M., Hollister, E.B. et al. 2009. 949 Introducing mothur: Open-source, platform-independent, community-supported software for 950 describing and comparing microbial communities. Appl. Environ. Microbiol. 75(23): 7537-7541.

951 Schut, G.J., Boyd, E.S., Peters, J.W., and Adams, M.W.W. 2012. The modular respiratory 952 complexes involved in hydrogen and sulfur metabolism by heterotrophic hyperthermophilic 953 archaea and their evolutionary implications. FEMS Microbiol. Rev. 37(2): 182-203. 
954 Siddiqui, K.S., Williams, T.J., Wilkins, D., Yau, S., Allen, M.A., Brown, M.V. et al. 2013.

955 Psychrophiles. Ann. Rev. Earth Planet. Sci. 41: 87-115.

956 Singh, A.K., Zhang, Y., Zhu, K., Subramanian, C., Li, Z., Jayaswal, R.K. et al. 2009. FabH

957 selectivity for anteiso branched-chain fatty acid precursors in low temperature adaptation in

958 Listeria monocytogenes. FEMS Microbiol. Lett. 301(2): 1-8.

959 Spurr, A.R. 1969. A low-viscosity epoxy resin embedding medium for electron microscopy. J.

960 Ultrastruct. Res. 26: 31-43.

961 Stamatakis, A. 2014. RAxML Version 8: A tool for Phylogenetic Analysis and Post-Analysis of 962 Large Phylogenies. Bioinformatics .

963 Suhre, K., and Claverie, J. 2003. Genomic correlates of hyperthermostability, an update. J. Biol. 964 Chem. 278(19): 17198-17202.

965 Suutari, M., and Laakso, S. 1994. Microbial fatty acids and thermal adaptation. Crit. Rev.

966 Microbiol. 20(4): 285-328.

967 Taylor, T.J., and Vaisman, I.I. 2010. Discrimination of thermophilic and mesophilic proteins.

968 BMC Struct. Biol. 10: S5.

969 Techtmann, S.M., and Robb, F.T. 2010. Archaeal-like chaperonins in bacteria. Proc. Natl. Acad.

970 Sci. U. S. A. 107(47): 20269-20274.

971 Terui, Y., Ohnuma, M., Hiraga, K., Kawashima, E., and Oshima, T. 2005. Stabilization of

972 nucleic acids by unusual polyamines produced by an extreme thermophile, Thermus

973 thermophilus. Biochem. J. 388: 427-433.

974 Thompkins, K., Chattopadhyay, B., Xiao, Y., Henk, M.C., and Doerrler, W.T. 2008.

975 Temperature sensitivity and cell division defects in an Escherichia coli strain with mutations in

$976 y g h B$ and $y q j A$, encoding related and conserved inner membrane proteins. J. Bacteriol. 190(13):

977 4489-4500.

978 Vos, M., and Didelot, X. 2009. A comparison of homologous recombination rates in bacteria and

979 archaea. The ISME journal 3(2): 199-208.

980 Wang, Z., Tong, W., Wang, Q., Bai, X., Chen, Z., Zhao, J. et al. 2012. The temperature

981 dependent proteomic analysis of Thermotoga maritima. PloS one 7(10): e46463.

982 Whitaker, R.J., Grogan, D.W., and Taylor, J.W. 2005. Recombination shapes the natural

983 population structure of the hyperthermophilic archaeon Sulfolobus islandicus. Mol. Biol. Evol.

984 22(12): 2354-2361.

985 Williams, T.A., and Embley, T.M. 2014. Archaeal "dark matter" and the origin of eukaryotes.

986 Genome Biology and Evolution 6(3): 474-481. 
987 Yilmaz, P., Parfrey, L.W., Yarza, P., Gerken, J., Pruesse, E., Quast, C. et al. 2014. The SILVA 988 and "All-species Living Tree Project (LTP)" taxonomic frameworks. Nucleic Acids Res. 42(D1): $989643-648$.

990 Zeldovich, K.B., Berezovsky, I.N., and Shakhnovich, E.I. 2007. Protein and DNA sequence 991 determinants of thermophilic adaptation. PLoS computational biology 3(1): e5.

992 Zellner, G., and Kneifel, H. 1993. Caldopentamine and caldohexamine in cells of Thermotoga 993 species, a possible adaptation to the growth at high temperatures. Arch. Microbiol. 159(3753): 994 472-476.

995 Zhang, Y., Thiele, I., Weekes, D., Li, Z., Jaroszewski, L., Ginalski, K. et al. 2009. Three996 dimensional structural view of the central metabolic network of Thermotoga maritima. Science 997 325(September): 1544-1549.

998 Zhang, Y., and Rock, C.O. 2008. Membrane lipid homeostasis in bacteria. Nat Rev Micro 6(3): $999222-233$.

1000 Zhaxybayeva, O., and Gogarten, J.P. 2004. Cladogenesis, coalescence and the evolution of the 1001 three domains of life. Trends Genet. 20(4): 182-187.

1002 Zhaxybayeva, O., and Doolittle, W.F. 2011. Lateral gene transfer. Current Biology 21(7): R242.

1003 Zhaxybayeva, O., Swithers, K.S., Lapierre, P., Fournier, G.P., Bickhart, D.M., DeBoy, R.T. et al. 1004 2009. On the chimeric nature, thermophilic origin, and phylogenetic placement of the

1005 Thermotogales. Proc. Natl. Acad. Sci. U. S. A. 106(14): 5865-5870.

1006 Zhaxybayeva, O., Swithers, K.S., Foght, J., Green, A.G., Bruce, D., Detter, C. et al. 2012. 1007 Genome sequence of the mesophilic Thermotogales bacterium Mesotoga prima MesG1.Ag.4.2 1008 reveals the largest Thermotogales genome to date. Genome Biol. Evol. 4(8): 700-708. 


\section{Figure Legends:}

1012

1013 Fig. 1. Distribution of organismal growth temperature adaptation across the three domains of life.

1014 Only major lineages with cultivated members (phyla for Bacteria and Archaea and supergroups

1015 for Eukarya) are shown. Most lineages contain organisms thriving at different temperature

1016 optima, suggesting that adaptation to temperature has happened multiple times independently.

1017 Given the uncertainty associated with the relationships among the shown taxonomic groups, their

1018 branching order is shown as unresolved, except for archaeal superphyla (Williams and Embley

1019 2014) and several deep-branching bacterial lineages (after SSU rRNA-based "The All-Species

1020 Living Tree", November 2014 release; (Munoz et al. 2011)). Eukaryotic supergroups are after

1021 Adl et al. (2012). The root of the tree is placed on a branch leading to bacterial phyla after

1022 Gogarten et al. (1989) and Iwabe et al. (1989), although an alternative location of the root

1023 between Archaea and Bacteria remains plausible (Dagan et al. 2010). Data on optimal growth

1024 temperature were obtained from the Integrated Microbial Genomes system (Markowitz et al.

1025 2014) and this figure does not represent an exhaustive overview of known lineages.

1026

1027 Fig. 2. Cells of Mesotoga prima MesG1.Ag.4.2. The toga can be seen ballooning out from the

1028 cell poles. The scale bar in the lower left corner corresponds to $0.5 \mu \mathrm{m}$. Cells of $M$.

1029 prima MesG1.Ag.4.2 were grown to exponential phase and samples prepared for microscopy as

1030 described by Spurr (1969). Images were acquired using a Philips Morgagni 268 transmission

1031 electron microscope (Philips-FEI, Hillsboro, Oregon, USA) operating at $80 \mathrm{kV}$ with Gatan Orius

1032 CCD camera.

1033 
1034 Fig. 3. Phylogenetic relationships among representative Thermotogae genera. 16S rRNA gene

1035 sequences were aligned using the NAST aligner in MOTHUR (Schloss et al. 2009) to the SILVA

1036 reference alignment (Yilmaz et al. 2014). Alignment sites with gaps were removed (resulting in a

$10371093 \mathrm{nt}$ alignment), and the maximum likelihood tree was reconstructed in RAxML (Stamatakis

1038 2014) under the GTR $+\Gamma$ substitution model. The newly proposed Thermotogae classification into

1039 three orders and four families is shown to the right of the tree (Bhandari and Gupta 2014). Note

1040 that based on the 16S rRNA phylogeny, Mesoaciditoga lauensis should be have its own order

1041 (Mesoaciditogales) and family (Mesoaciditogaceae). Published optimal growth temperatures for

1042 each genus are shown. Taxonomic names of hyperthermophiles, thermophiles and mesophiles

1043 are depicted in bold black, black, and grey fonts, respectively. Bootstrap support values (out of

1044100 replicates) are shown at the nodes only for values above 70 . The tree was rooted with the

1045 following taxa as an outgroup (collapsed into a wedge): Alkalliphilus auruminator (AB037677),

1046 Marinithermus hydrothermalis (AB079382), Persephonella marina (AF188332), Aquifex

1047 pyrophilus (AQF16SRRN), Aquifex aeolicus (AE000751), Clostridium thermocopriae

1048 (CLORG16SAA), Clostridium botulinum (NC_009495), Flexibacter flexilis (FBCRRB),

1049 Thermus thermophilus (X07998) and Dictyoglomus thermophilum (X69194). 